\title{
Um estranho em Goa: viagem transitiva a um Oriente em demanda*
}

\section{Um estranho em Goa [A stranger in Goa]: transitive journey to a sought-after Orient}

\author{
INOCÊNCIA MATA*
}

Resumo: A obra de José Eduardo Agualusa (Huambo, Angola, 1960) tem a particularidade de não se deter nem numa prática genológica (a sua bibliografia inclui romances, contos, crónicas, apontamentos narrativos e alguma poesia) nem numa área temática ou uma geografia - espacial, temporal ou cultural. Com efeito, as suas personagens são normalmente marcadas por descontinuidades geográficas e históricas, com trajectórias que se cruzam numa "perspectiva de contacto" que potencia conexões e interacções de vária ordem entre sujeitos diferentes, em espácio-temporalidades diversificadas. Tais arborescências ficcionais, sobretudo romanescas, embora nem sempre suficientemente amplificadoras para criar sentidos cosmopolitas, são construtoras de sujeitos transitivos e geradoras de significados transculturativos. É o que acontece em Um Estranho em Goa, romance que, oscilando entre narrativa de viagens e construção ficcional do real, apresenta diferentes modalidades da reinvenção da identidade goesa, trazendo à cena literária trânsitos e conexões orientais num processo de resgate das margens das representações político-ideológicas do outro, apresentado na sua outridade - portanto, como possibilidade do diverso.

Palavras-chave: Corumbá, Brasil, Goa, Oriente - sujeitos transitivos - narrativa de viagens - ficcionalização do real - "zona de contacto"

\footnotetext{
Este é um texto resgatado dos escaninhos de comunicações não publicadas. Uma versão dele foi apresentada na Jornada Internacional O Oriente nas Literaturas de Língua Portuguesa (4 de dezembro de 2009), cuja organização coube às Áreas 2 e 3 do Centro de Literaturas e Culturas Lusófonas e Europeias (CLEPUL) da Faculdade de Letras da Universidade de Lisboa, Portugal.

** Professora na Faculdade de Letras da Universidade de Lisboa, Portugal, na área de Literaturas, Artes e Culturas. Presentemente, em licença para o exercício de funções transitórias na Universidade de Macau, China, onde é Subdiretora do Departamento de Português da Faculdade de Artes e Humanidades e Coordenadora do Programa de Doutoramento, PhD in Literary and Intercultural Studies (Portuguese).
} 
Abstract: The work of José Eduardo Agualusa (Huambo, Angola, 1960) has the particularity of neither being limited to a single genre (his bibliography includes novels, short stories, chronicles, narrative notes and some poetry) nor to a single theme or area, be it spatial, temporal or cultural. Indeed, his characters are usually marked by geographical or historical discontinuities and intersecting trajectories within a "perspective of contact" that enablesconnections and interactions fo various sorts between different subjects in diverse spatio-temporal frames. Such fictional arborescences, especially present in his novels, though not always to a degree that generates cosmopolitan ramifications, construct transitive subjects and generate transcultural meanings. Um Estranho em Goa [A Stranger in Goa] is a case in point. Oscillating between the travel narrative and the fictionalisation of the real, the novel reinvents Goan identity in various ways, bringing onto the literary scene oriental exchanges and interlinkages and recovering the margins of political and ideological representations of the other, never losing sight of its otherness, in other words its potential as a site of diversity.

Keywords: Corumbá, Brasil; Goa, Orient - transitive subjects - travel narratives fictionalization of the real - contact zone 
O Ocidente, assim como sua contrapartida oriental, é uma construção fictícia baseada em mitos e fantasias. De uma perspectiva geográfica, o conceito é relativo [...] é a política que determina as configurações geográficas.

Ella Shohat \& Robert Stam

utor de uma já extensa bibliografia (que inclui romances, contos, crónicas, apontamentos narrativos e alguma poesia), José Eduardo Agualusa (Huambo, Angola, 1960) é um escritor que não se detém numa área temática ou uma geografia - espacial, temporal ou cultural. Em cada romance, em cada colectânea de contos ou narrativas breves, as suas personagens são marcadas por descontinuidades geográficas e históricas, com trajectórias que se cruzam numa "perspectiva de contacto" que potencia conexões e interacções de vária ordem entre sujeitos diferentes, em espacio-temporalidades diversificadas. Tais arborescências ficcionais, sobretudo romanescas, embora nem sempre suficientemente amplificadoras para criar sentidos cosmopolitas, são construtoras de sujeitos transitivos e geradoras de significados transculturativos.

Com efeito, é uma constante na obra romanesca de José Eduardo Agualusa um insistente trabalho de refracção e refiguração de novas identidades, outras alteridades, diferentes daquelas a que o Ocidente, empírico e literário, está habituado. É característica da sua obra o discurso performativo que encena polaridades culturais e as devolve à consciência multicultural e dita cosmopolita - que, no entanto, se fecha ao estrangeiro. ${ }^{1} \mathrm{~A}$ sua obra tem vindo a ser marcada pela confluência da tríade "visão, vivência e escopo", quesitos, segundo Maria Leonor Buescu, do exotismo (BUESCU, 1997, p. 566). Porém, um exotismo que é mais a celebração do diverso, pois o emissor (narrador/autor textual), porque respeita a "singularidade diferencial da alteridade", comporta-se como um exo$t a$, aquele que sente prazer estético na observação do diverso - e não como um turista ou um folclorista (SEGALEN, 1978). Creio, por isso, que, na demanda do Oriente, Um estranho em Goa encena o processo de resgate das margens das

1 Estudos parecem apontar para uma distinção entre outro e estrangeiro. Julia Kristeva, por exemplo, considera que o estrangeiro é marcado pela indiferença (até agressividade, que produz passiva ou activamente), sendo que o outro, propulsor da alteridade, é marcado pela diferença (KRISTEVA, 1989, p. 15 ss.). 
representações político-ideológicas do outro, minoritário ou não, para que se apresente não enquanto agente de alteridade, mas na sua outridade - portanto, como possibilidade do diverso.

\section{Conexões transtextuais: dois narradores à procura de uma personagem (de Corumbá, Mato Grosso, a Goa)}

Vim à procura de uma personagem. Quero saber como termina a história dele.

José Eduardo Agualusa

No seu livro Fronteiras perdidas: contos para viajar (1999), José Eduardo Agualusa elege como epígrafe da colectânea a seguinte afirmação de Manoel de Barros, o poeta matogrossense que faz parte do roteiro de entrevistas do narrador-autor do conto "Plácido Domingo contempla o rio, em Corumbá (Corumbá, Brasil)", o sexto dos dezasseis contos desta colectânea: "Há histórias tão verdadeiras que às vezes parece que são inventadas" (BARROS, 2004, p. 69).

Se este pensamento sintetiza, de certa maneira, toda a filosofia da arte literária de José Eduardo Agualusa (ele que é também um cultor da ficção histórica - veja-se A conjura, 1989; Estação das chuvas, 1996; O ano em que Zumbi tomou o Rio, 2002; A rainha Ginga: e de como os africanos inventaram o mundo, 2014; ou, até, Teoria geral do esquecimento, 2012), esta lógica domina em Um estranho em Goa: este romance mistura ficção e factos da história de Angola e de Goa, e percorre os trilhos da identidade cultural da comunidade goesa, conciliando o étnico e o territorial. ${ }^{2} \mathrm{O}$ que é acentuado pelo facto de a narrativa ser precedida de um mapa de Goa que cartografa os lugares de trânsito do narrador no seu rastreamento da localização de Goa na União Indiana. É interessante esta "armação cartográfica" numa estrutura romanesca pois a "mensagem" parece-me evidente: o "espaço textual" das palavras ganha sentido com o complemento do "espaço geométrico" do mapa. Esta representação cartográfica transforma

2 Baseio-me na distinção que Anthony D. Smith faz dos nacionalismos: para ele, existem basicamente dois tipos de nacionalismos, territorial e étnico (SMITH, 1997 [1991], p. 107.). 
o texto em "espaço assimilável, permitindo apreendê-lo como realidade passível de ser medida, ordenada ou planificada" (CURVELO, 2003, p. 114).

Se a "materialização visual" do território sobre o qual se vai falar resulta em humanização do espaço, também lhe confere uma tangibilidade identitária, porque o espaço se culturaliza na medida em que se apresenta como entidade não natural, entendida como entidade trabalhada pelo homem. A dimensão cultural do espaço evidencia-se na "legendagem", resumindo não apenas um saber geográfico sobre a região, mais ainda sugerindo, simbolicamente, o trânsito de que resultou aquela identidade étnica e territorial que se baseiam - esse saber e essa simbólica transicional - numa lógica de teor histórico-ideológico. É nessa lógica que se insere a exposição da dualidade que acompanha toda a narrativa, Goa/União Indiana, e que indicia um singular enfrentamento de visões da história que vai refazendo as estratégias de identificação e as "zonas de contacto" ${ }^{3}$ constituintes do articulado identitário goês, nas suas complexas relações entre sensibilidades.

A afirmação de que a representação da factualidade é uma característica fundacional desta narrativa fica aquém da sua dimensão armadilhante. Primeiro porque a dimensão do histórico é-o apenas nas figurações históricas (a história do período imediato pós-independência de Angola e a história da relação entre Goa e a União Indiana), suportadas por um manancial historiográfico como sejam as crónicas, itinerários e livros de viagem assim como apontamentos etnográficos e alguma - pouca - referência literária. ${ }^{4}$ Diversas e diversificadas são, pois, as fontes em que se apoia o narrador: Richard Burton (Goa and the Blue Mountains), o padre (jesuíta) Francisco de Souza (Oriente Conquistado ${ }^{5}$ ), Fran-

\footnotetext{
3 Expressão da lavra de Mary Louise Pratt definida como "espaços sociais onde culturas díspares se encontram, se chocam, se entrelaçam uma com a outra, frequentemente em relação extremamente assiméticas de dominação e subordinação" (PRATT, 1999, p. 27).

4 É interessante, neste contexto, não haver qualquer referência a Orlando da Costa (1929-2006), um dos mais conhecidos escritores goeses, com uma obra que tematiza as memórias da história colonial no Estado da Índia, mapeando as sensibilidades identitárias decorrentes da relação colonial, por um lado, e as relações pós-coloniais, com a União Indiana, por outro, a saber: os romances $O$ signo da ira (Prémio Malheiros da Academia das Ciências de Lisboa, 1961); O último olhar de Manú Miranda (2000); e o drama Sem flores nem coroas (1967).

5 O título do livro é: Oriente Conquistado a Jesu Christo pelos Padres da Companhia de Jesus em Goa, com uma visão de Goa que revelava um profundo desprezo pelos brâmanes goeses, como se pode ver na seguinte afirmação: "There are no other wicked people, or more pervese than these" (apud SOUZA, 1997, p. 379).
} 
cisco Pyrard de Laval (Viagem de Francisco Pyrard de Laval às Índias Orientais, 1601-1611); mas também estudos científicos de conhecidos historiadores como Charles Boxer, Pratima Kamat, Robert Ambelain (Os arcanos negros do hitlerismo), Tristão de Bragança Cunha (A desnacionalização dos goeses), do filólogo Sebastião Rodolfo Dalgado (Glossário luso-asiático); assim como testemunhos do escritor Mário Cabral de Sá, dos freedom-fighters Nagesh Karmali e Krishnarao Rane (da Associação dos Combatentes de Goa, Damão e Diu), Percival de Noronha ${ }^{6}$ (que o narrador descreve como "o perfeito cavalheiro da velha aristocracia católica goesa"). Conta-se ainda, nesse repertório testemunhal, figuras que, se não identificáveis explicitamente como reais, são historicamente verosímeis, tais como o solícito motorista Sal, Pedro Dionísio, D. Marcelina Cabral e o velho Mendes, o livreiro. E, claro, a mais privilegiada voz testemunhal desse processo de demanda de um Oriente que se faz presente mais por vozes captadas de leituras temperadas por uma "acção transitiva": trata-se de Enoque, nome com que era conhecido, em Goa, Plácido Domingo, aliás, o Comandante Maciel, antigo guerrilheiro do MPLA que já fora Capitão Afonso Domingo, militar do exército português, que em certo momento da história da Angola pós-colonial se fora refugiar em Corumbá.

Para além da interessante contaminação biográfica presente na construção do perfil do narrador (pelo nome, José, pela personalidade questionadora, inquisitiva, irónica, persistente, pelos hábitos e rituais, pelas referências e relações pessoais, pelos lugares de vivência e de convivência, pelos diversos "locais de cultura" implícitos no conhecimento cultural e social, reconhecivelmente plasmados do autor empírico), torna-se imperativa a convocação de semelhanças entre as reflexões deste narrador e as do escritor José Eduardo Agualusa. Retenhamos um exemplo desta contaminação em três andamentos:

a. Há algum tempo que pretendo contar a história de Plácido Domingo. Hesitei em fazer isso antes porque já existe o Plácido Domingo, o tenor, mas nunca me conformei. Certos nomes deviam ser obedecidos, isto é, deviam implicar um destino (AGUALUSA, 1999, p. 45)

6 Funcionário do Departamento de Informação e Turismo no regime colonial. Cf. Souza (1997, p. $380)$. 
b. O personagem principal, chamado Plácido Domingo, nasceu numa crónica. Porque eu acho que um homem chamado Plácido Domingo tem de ter outro destino. Há nomes que têm um destino. (AGUALUSA, 2004, p. 20-21)

c. Foi também por isso que fiz esta viagem. Vim à procura de um personagem. Quero saber como termina história dele.

[...]

No meu conto Plácido Domingo, um velho de pele dourada, seco, gestos demorados, a fala antiga e cerimoniosa de um cavalheiro do século dezanove, vive em Corumbá, pequena cidade nas margens do Rio Paraguai, junto à fronteira com a Bolívia. Nessa altura, é claro, eu já sabia que Plácido Domingo se havia escondido em Goa. (AGUALUSA, 2007, p. 13-14)

O segundo excerto (b) é o começo do conto "Plácido Domingo contempla o rio, em Corumbá (Corumbá, Brasil)", retirado de Fronteiras perdidas, de 1999, cujo início é retomado como espolete da história que agora se vai contar (Um estranho em Goa, 2000), em complexas conexões transtextuais actualizadas em relações meta- e intertextuais. Com efeito, os dois últimos excertos (conto e romance) relacionam-se tanto pelos comentários do terceiro (c) sobre o segundo (b) quanto pela memória que o aquele (c) tem deste (b), em alusões, citações e transformação - sobretudo no sentido em que Genette pensa a intertextualidade: "uma co-presença de dois ou vários textos, isto é, eideticamente e muito frequentemente, pela presença efectiva de um texto em outro texto" (1982, p. 8).

O emissor é um narrador autodiegético que, recuperando a performance anterior, se desdobra em sujeito da escrita e observador da realidade histórica, convocando nessa posição o autor e a memória do escritor, como se vê logo no início quando é referida a "obsessão" do escritor: "Vim à procura de uma personagem. Quero saber como termina a história dele" (AGUALUSA, 2007, p. 13).

O primeiro "encontro" passara-se em Fronteiras perdidas, em "Corumbá, pequena cidade nas margens do rio Paraguai, junto à fronteira com a Bolívia" (ibidem, p. 14), onde o escritor encontrara Plácido Domingo, enigmática figura da luta de libertação de Angola, vivendo "sob a mansidão de um quotidiano sempre igual, um antigo segredo" (ibidem, p. 14), tentando reconstruir a sua velha cidade do Dondo, nas margens do rio Kwanza. ${ }^{7}$

7 Utilizo a ortografia angolana em vez da portuguesa, utilizada pelo autor. 
A busca é, assim, o primeiro móbil desta narrativa que o enunciador assume desde o início (ibidem, p. 13) e vai reiterando esse perfil inquisitivo ao longo da narrativa: "Nunca deixo de procurar aquilo que os outros acham que não tem interesse para mim" (ibidem, p. 24).

A assunção desta motivação faz desta narrativa um exercício de reflexão sobre a criação literária, em que a constante oscilação e constantes saltos da entidade enunciadora entre os níveis narrativos tornam temerária uma classificação definitiva deste narrador.

Porém, porventura a mais sólida evidência da temeridade classificatória desta narrativa, que advém também da sua ambiguidade genológica (como se verá mais adiante), é-nos dada pelo sujeito de enunciação, numa das suas muitas transposições metalépticas: "Dêem-me dois ou três factos, ou nem mesmo isso, apenas vagos indícios, e eu construo um romance. Aliás, quanto menos factos melhor, a realidade atrapalha a ficção" (ibidem, p. 57).

(Este narrador agualusiano estabelece uma produtiva interlocução, de teor metapoético, com outro sujeito poético em demanda do Oriente, procurando reconstituir os fiapos de uma pertença a disseminar-se pelo arco-íris da figurações identitárias de Moçambique: refiro-me a Janela para o Oriente, de Eduardo White [1999]: "Eu nada sabia desta remota possibilidade, deste lírico fervor que guardo pela imaginação").

\section{Um estranho em Goa: uma narrativa de viagens?}

A viagem envolve e implica sempre a busca ou demanda de um objecto, de um alguém ou de um algures, cujos símbolos são, no entanto, extremamente variáveis.

Maria Leonor Carvalhão Buescu

A crítica, sobretudo a jornalística, foi muito categórica em considerar Um estranho em Goa uma narrativa de viagens. Porém, ainda que essa classificação possa ser vista como "apressada", o certo é que o enquadramento genológico desta narrativa é um exercício desafiante. Com efeito, para além do aparato romanesco e a intencionalidade textual, aliados ao corpus paratextual (por exem- 
plo, a anotação de que "o Autor beneficiou de uma bolsa de criação literária concedida pela Fundação Oriente") e as conexões com textos literários acima referidas, a complexidade que caracteriza a entidade instituidora da narrativa, que pode ser actualizada na interrogação "José, que sujeito de enunciação?", são qualidades formais a ter em conta nesse exercício de categorização genológica.

Em todo o caso, se a crítica parece consensual na inclusão deste romance no género "literatura de viagens" - e, como se sabe, a recepção é uma instância que interfere não apenas na fundação do "local da cultura" do texto e até na sua lógica genológica, como condiciona o protocolo de leitura que o emissor estabelece com o leitor -, vale a pena desfiar os quesitos desta categoria. Na verdade, em Um estranho em Goa o narrador-jornalista está constantemente em viagem: de Pangin a Anjuna, de Candolim a Velha Goa, da Ilha de Divar a Baga, de Rachol a Pondá, antes, Rio de Janeiro, Olinda, Campo Grande, Huambo, Luanda. Existe, com efeito, quase constituindo um traço ontológico da voz narrante, uma frenética e sistemática deslocação que se institui como categoria estruturante da narrativa.

Neste contexto, salta à vista um aspecto muito interessante que é o jogo de espelhos engendrado pelas metamorfoses da perspectiva narrativa, que se actualiza na transformação da diferença e da direcção do olhar do enunciador, que vai convocando "deslocamentos metonímicos" e "condensações metafóricas" (Abdul JanMohamed). É, por isso, significativa a passagem do olhar do viajante, que começa por se deter na paisagem de coqueiros e arrozais, ao do turista, que se sente atraído por aquilo a que Fernando Cristóvão designou como "tropismo em direcção à natureza" (CRISTÓVÃO, 1999, p. 28), ao olhar do "repórter" que se divide entre o "interesse cronístico" do jornalista, à observação do ficcionista em relação à criatividade estética e ao imperativo do conhecimento de outras geografias culturais que a curiosidade intelectual exige. É então que começa a realizar-se a acção transitiva da observação do narrador: o narrador-personagem, cuja mente inquisitiva vai perscrutando os meandros identitários da antiga capital do Estado da Índia e desvelando as visões contrastantes da identidade de Goa que Percival de Noronha considerara, amargamente, "um pequenino estado dentro de um país enorme como é a Índia” (AGUALUSA, 2007, p. 15).

Apesar de o narrador anunciar como razão da sua viagem a Goa a busca de uma figura, Plácido Domingo, porque quer saber como termina a história dele (ibidem, p. 13), a verdade é que esse objectivo não é um fim, mas um meio pois 
a descoberta do outro parece ser o objectivo a que a viagem se submete. Assim, pode dizer-se que, não obstante Um estranho em Goa ser uma construção ficcional do real efectivada numa "operação textual" (KRYSINSKI, 1981, p. 7), não deixa de ser narrativa de viagem de formação cultural e reflexão intelectual porque todos os eventos se desenvolvem a partir de deslocações. Parafraseando Fernando Cristóvão, em "Viagem erudita, de formação e de serviço", a propósito deste tipo do subgénero literatura de viagens, que se poderia aproximar da modalidade narrativa de busca cultural, em Um estranho em Goa "a aquisição de conhecimentos é a preocupação maior" e a cultura humanística adquirida a cada passo vai provocando novas ideias e levantando novas hipóteses (CRISTÓVÃO, 1999, p. 49).

É essa mente inquisitiva do narrador, dinamizada pelo factor da curiosidade, que faz desta narrativa de viagem uma acção transitiva. Mesmo porque "viagem [é] diferente de pura e simples deslocação no espaço: a viagem envolve e implica sempre a busca ou demanda de um objecto, de um alguém ou de um algures, cujos símbolos são, no entanto, extremamente variáveis (BUESCU, 1997, p. 567).

\section{Modalidades da reinvenção da identidade goesa: trânsitos e conexões orien- tais}

Os mitos imperiais continuam gerando significados, desejos e ações.

Mary Louise Pratt

Cartografando as dúplices heranças culturais e querenças ideológicas, o jornalista vai pesquisando e dando sentido às conexões transculturativas que se evidenciam na construção identitária da comunidade goesa. Esse percurso é complementado com outras fontes, como sejam representações, sobretudo inscritas em monumentos arquitectónicos, que falam da história colonial de Goa, mas também inseridas em alguns poucos rituais referidos (como a Feira de Anjuna, o Diwali ou o Festival das Luzes em Panjin, a Procissão de São Francisco Xavier da Velha Goa). Na viagem, em que tudo ganha sentido, em que "nada era inútil, tudo servia para aumentar o saber" (CRISTÓVÃO, 1999, p. 49), o viajante torna-se obcecado pelo desenrolar dos acontecimentos: corre perigo de vida, os 
acontecimentos ultrapassam-no (como no caso da mirabolante e inacreditável tentativa de venda das relíquias de São Francisco Xavier, no caso o coração; ou a morte de seu amigo Jimmy Ferreira, o proprietário do bar Bicho da Sede), os seus interlocutores nem sempre são por si escolhidos. Qual herói trágico, embora pícaro, simplesmente não consegue desistir, não conseguindo reverter o seu destino...

Com efeito, é o próprio narrador a não (se) compreender por que o jornalista não se vai embora (conforme o aconselhara Plácido Domingo em agoirento aviso) em círculos de convergência com deriva metaléptica:

Procurei ordenar o caos. O que fazia ali? Já tinha a verdadeira história de Plácido Domingo. Podia, como lhe prometera, regressar ao Rio de Janeiro. Era uma boa história, embora, de certo modo, lamentasse o desfecho. Teria preferido que o velho fosse realmente um traidor. Seria perfeito como metáfora do Diabo - o supremo traidor. (AGUALUSA, 2007, p. 119)

É aqui que o factor da curiosidade revela a sua dimensão intelectual e potencia a dinâmica da acção transitiva: ao mesmo tempo que quer conhecer uma história de vida (a de Plácido Domingo) e a história de uma comunidade (a goesa), quer perceber-se e conhecer o eu. E ao descobrir o outro conhece o eu, que não pertence à comunidade do outro: afinal, José, o narrador-jornalista, reconhece-se como um estranho em Goa. Já em 1982, em A conquista da América: a questão do outro, referindo-se à descoberta do outro pelo $e u$, tomando como paradigma de uma "aç̧ão intransitiva" a descoberta da América por Colombo, Tzvetan Todorov afirma: "Podem descobrir-se os outros em si mesmo, e perceber que não se é uma substância homogênea, e radicalmente diferente de tudo o que não é si mesmo; eu é um outro. Mas cada um dos outros é um eu também, sujeito como eu" (TODOROV, 2003, p. 3).

É por isso que, como atrás ficou sugerido, a busca do outro em Um estranho em Goa não se torna exótica embora, segundo Maria Leonor Carvalhão Buescu, que apresenta "pressupostos irrecusáveis" deste registo genológico, se possa pensar no exotismo como contrapartida do etnocentrismo, na medida em que faz funcionar, como categoria tutelar, o distanciamento espacial, social, cultural, antropológico, estético (BUESCU, 1997, p. 567). Isso porque, de novo parafraseando Todorov - agora em Nous et les autres - não se procede à valorização, celebração ou condenação de um conteúdo estável, nem se procede à representação de uma comunidade e uma cultura definidas exclusivamente pela sua 
relação com o observador (TODOROV, 1989, p. 297). Assim, mais importante do que afirmar uma visão de Goa, o que é feito é a representação de multiplicidades identitárias, "arborescência nos rizomas, empuxos rizomáticos nas raízes" (DELEUZE; GUATTARI, 2007, p. 31).

Ainda na referenciação da construção narrativa deste romance, assinalem-se outras viagens transtextuais no sentido de "transcendência textual do texto [...] tudo o que estabelece com ele qualquer relação, manifesta ou secreta, com outros textos" (GENETTE, 1982, p. 7): evidenciam-se conexões transtextuais com Estação das chuvas (1996), em que Lídia do Carmo Ferreira, personagem principal daquela narrativa, se transforma, nesta, em informadora do paradeiro de Plácido Domingo, que, por sua vez, é informado do seu desaparecimento, vale dizer sua morte, nos fatídicos acontecimentos em Luanda de 1992 (AGUALUSA, 2007, p. 49); outro exemplo é a viagem, em Fronteiras perdidas, de Corumbá a Goa, do rio Kwanza ao rio Paraguai, ao rio Zuári e ao rio Mandovi.

Há ainda um aspecto que faz esta narrativa destacar-se do subsistema em que se integra: a não dominância da descrição que a transformaria, e aos referentes, em lugares estáticos incompatíveis com a dinâmica da transitividade, de mútuo (re)conhecimento, que esta narrativa sugere, evidenciada na narração, que, vale lembrar, é uma componente entendida como "procedimento representativo dominado pelo expresso relato de eventos e de conflitos que configuram o desenvolvimento de uma acção" (REIS; LOPES, 1994, p. 248). Não se trata, portanto, apenas de dinâmica espacial - o que eventualmente a deslocação conferiria: existe em Um estranho em Goa uma dinâmica temporal que afecta terrenos que se reportam a formas de relacionamento com o referente. E essas formas vão-se modificando de acordo com a aprendizagem que, como já foi referido, o olhar do enunciador vai revelando.

Por outro lado, as visões contrastantes sobre a (auto-) representação goesa, que se podem resumir na terminologia usada consoante o lugar ideológico de quem fala - "Invasão" vs. "Libertação" (AGUALUSA, 2007, p. 85) - são enunciadas por um lado por Sal, D. Marcelina Cabral e Percival de Noronha e, por outro, pelos freedom fighters e o escritor Mário Cabral de Sá e revelam um terreno movediço de visões contrastantes sobre o mesmo. Cumpre-se deste modo o desígnio de Hayden White que, no seu exercício de questionamentos metodológicos, afirma em The content of the form: narrative discourse and historical representation, que um acontecimento histórico é aquele que é susceptivel de, 
pelo menos, duas narrações da sua ocorrência (WHITE, 1992, p. 20). E se pensarmos que este posicionamento de White não refere apenas duas perspectivas, mas também duas modalidades discursivas, duas formas de relatar, dois modos de textualizar, enfim, duas realizações discursivas - a histórica e a ficcional, ou, em termos de modalidade de conhecimento, a científica e a artística -, torna-se mais estimulante a confrontação que o narrador faz das diversas subjectividades nos vários "locais culturais" para perceber a complexidade da identidade goesa, situada num ponto de cruzamentos tensos ideológicos entre o Oriente e o Ocidente.

Na referenciação de suas identidades, tanto Sal quanto D. Marcelina Cabral fazem a articulação social da diferença, da perspectiva da minoria em que se inserem os católicos naturais e os (luso-)descendentes, designação que, por si só, revela a primazia de Portugal na construção da imagem de identidade comunitária - os "olhos do império", de que fala Mary Louise Pratt, pela continuidade da lógica da dominação na articulação do discurso sobre a identidade. Tal se processa por via de uma negociação complexa, em que os sujeitos se apropriam de instâncias metropolitanas de que resulta uma "expressão auto-etnográfica", isto é, conjunto de "representações de si mesmos de forma comprometida com os termos do colonizador" (PRATT, 1999, p. 33). Dona Marcelina, por exemplo, que chorara quando, em 1961, a bandeira portuguesa foi arriada, recusava-se a aprender inglês, sentia-se portuguesa e apenas lamentava não possuir passaporte português (AGUALUSA, 2007, p. 65). No arco tenso entre esta sensibilidade, de que Dona Marcelina e Sal são representantes, e a da "futilidade de aprender a língua portuguesa" (Teotónio R. de Souza), situava-se uma outra, porventura mais transversal segundo a qual Goa "era um pequeno território sem expressão militar e de reduzido interesse económico, onde gerações de portugueses criaram e enraizaram um tipo sui generis de colonização" (MORAIS, 1995, p. 29). Essa particularidade encontra, à jusante, a teoria da "vocação tropicalista" da cultura portuguesa propugnada por Gilberto Freyre quanto ao "mundo que o português criou": "Mundo que, como conjunto de valores essenciais de cultura, como realidade psico-social, continua a existir. Sobrevive à desarticulação do império simplesmente político. Resiste à pressão de outros imperialismos meramente económicos ou políticos" (FREYRE, 1951, p. 30).

Porque a autoetnografia envolve colaboração parcial com a apropriação do léxico do conquistador, na articulação da diferença, a língua portuguesa e a re- 
ligião católica funcionam como construtores do étnico. Em todo o caso, nem sempre os que a reivindicam possuem estes quesitos: Sal, por exemplo, não fala português, enquanto os filhos de $D$. Marcelina têm uma relação ambígua com a pátria - que mal conhecem. Plácido Domingo resume do seguinte modo esse imbróglio identitário: "Sabe o que é um judeu? É alguém a quem lembram que é judeu. Provavelmente esses indivíduos não se sentem indianos porque todos insistem em lhes dizer que são portugueses" (AGUALUSA, 2007, p. 68).

Lembra Arjun Appadurai, com efeito, que "o passado deixou de ser uma pátria a que regressar numa simples operação da memória. Tornou-se um armazém sincrónico de enredos culturais, uma espécie de central de castings temporal a que recorrer apropriadamente" (APPADURAI, 2004, p. 47)... Por seu turno, Mário Cabral e Sá e os freedom-fighters Nagesh Karmali e Krishnarao Rane são os agentes desse processo de "perspectiva de contacto" que põe em relação os sujeitos constituídos nas e pelas relações uns com os outros" (PRATT, 1999, p. 32). Nesse processo também a memória desempenha um papel que procura conferir significação étnica à mestiçagem cultural indo-portuguesa, mais imaginada do que histórica, se considerarmos os seus testemunhos como constituintes de subjectividades identitárias:

[Mário Cabral e Sá] - Quando estávamos no Liceu era comum os mestiços maltratarem os nossos companheiros hindus. Tiravam-Ihes os chapéus, mandavamnos baixar as calças, perguntavam-Ihes: vocês rapam a pentelheira ou não?, e a gente ficava chocada. Havia portanto uma afinidade rácica entre católicos e hindus, contra os descendentes, que ultrapassava a religião. (AGUALUSA, 2007, p. 62-63)

A ideia de ser a identidade goesa um compromisso entre a matriz indiana e a portuguesa, resultando um "produto" de proveniência transcultural, em constante negociação, percorre toda a narrativa. Atente-se no seguinte diálogo entre o narrador e Plácido Domingo:

- Hoje sente-se indiano?

- Não, indiano não, mas às vezes sinto-me goês...

-E português?

- Isso já não sei. O que um português? (ibidem, p. 50) 
O próprio narrador, apanhando na contramão do lugar de inquiridor, confessa a sua hesitação:

A pergunta apanhou-me desprevenido. Hesitei:

- Bem, antes de mais, suponho, um europeu... (ibidem, p. 50)

Se por este diálogo com Plácido Domingo o narrador capta a dimensão oscilante da processualidade identitária, entre a negação e a afirmação, a recusa e aceitação, D. Marcelina Cabral é a figura emblemática da "mímica colonial" de que fala Homi Bhabha para quem "a mímica emerge como uma das estratégias mais ardilosas e eficazes do poder e do saber coloniais" (BHABHA, 1998, p. 130). D. Marcelina é uma personagem de dimensão trágica pois tem a profunda consciência do seu destino de expatriada em própria terra, desterritorializada ideologicamente, que nem sequer pôde regozijar-se com o facto de pelo menos um dos filhos se casasse com uma descendente. Lembra ainda Bhabha que "a mímica colonial é o desejo de um Outro reformado, reconhecível, como sujeito de uma diferença que é quase a mesma, mas não exatamente" ${ }^{8}$ (BHABHA, 1998, p. 130). A mímica colonial manifesta-se e condiciona as hierarquias de valor nos diferentes sistemas de significação societária, na contramão dos pluralismos pós-coloniais.

\section{Uma narrativa inclusiva: encenando a diversidade}

A escrita da história pressupõe modos plurais de estar no mundo.

Dipesh Chakrabarty

Nos seus estudos sobre "Histórias de minorias, passados subalternos", Dipesh Chakrabarty afirma que "a escrita da história pressupõe modos plurais de estar no mundo" (2005, p. 215). Esta afirmação considera, no seu enquadramento epistemológico, o questionamento de narrativas monolíticas e as modalidades de construção histórica nas relações entre maiorias e minorias (mesmo se

8 Meu sublinhado. 
Chakrabarty considere, como antes fizera Albert Memmi em Portrait du colonisé, précédé du portrait du colonisateur (1957), que minoria e maioria são construções - ideológicas, acrescento).

Consciente desse reconhecimento, não existe em Um estranho em Goa uma relação de exclusão entre as duas representações identitárias acima referidas, antes sendo elas complementares na medida em que expressam duas visões de novas configurações da identidade territorial de Goa. Como afirma Mary Louise Pratt, "a expressão auto-etnográfica [é] um fenômeno extensivo da zona de contato e tornar-se-á um elemento importante para o esclarecimento das hipóteses de subjugação imperial e resistência tais como vistas desde o local dos eventos $(1999$, p. 35). Através de um constante trânsito geográfico do narrador, que acaba por funcionar como porta-voz de diferentes entidades e sensibilidades ideológicas, vai-se revelando o mapeamento dessas subjectividades, relatando, indagando a multiplicidade de identificações várias e as complexas redes de papéis sociais e culturais que se cruzam e podem agrupar-se em dois pares binários: indianos e goeses, hindus e católicos. Estes pares, embora apresentados pelos seus representantes como excludentes, evocam, simultaneamente noções muito diferentes, integração na diferença e luso-tropicalismo, no sentido de assimilação. Apesar do que afirma Teotónio R. de Souza: "Since we have touched on the cultural dialogue, the Portuguese presence in India did not vanish without leaving strong traces" (SOUZA, 1997, p. 379).

Evoca também, no entanto, o "rejeicionismo endurecido" (SAID, 2004, p. XXIII) dos descendentes e de uma parcela dos católicos naturais em relação à União Indiana, de que faz parte desde 17 de Janeiro de 1961, dá substância à tradição do orientalismo, na definição do próprio Said "um modo de relacionar-se com o Oriente que se baseia no lugar especial que o Oriente ocupa na experiência ocidental" (ibid, p. 1). Essa modelação da ideia de constructo ideológico é tanto mais significativa quanto ela dialoga com a afirmação de Ella Shohat e Robert Stam: "O Ocidente, assim como sua contrapartida oriental, é uma construção fictícia baseada em mitos e fantasias. De uma perspectiva geográfica, o conceito é relativo [...] é a política que determina as configurações geográficas" (SHOHAT; STAM, 2006, p. 37).

Tal relativismo nota-se quando a historiadora Pratima Kamat fala do número maior de hindus depois da ocupação, fazendo notar que a população católica constituía $37 \%$ contra os $20 \%$ actuais. Porém, Teotónio R. de Souza afirma que, 
quando do final do regime colonial, em 1961, os hindus constituíam $61 \%$ da população (SOUZA, 1997, p. 377). Ainda no contexto do relatividade do olhar, porventura o trecho mais interessante desta narrativa de viagem é a reflexão do narrador viajante, de visita ao Oráculo de Shri Manguesh, por sugestão do velho Mendes, livreiro fluente em português:

O linga, objecto de pedra ou madeira em forma de falo - o pénis erecto de Shiva, a poderosa força criadora do macho, o eixo do mundo -, pode ser visto em numerosos templos hindus. O Templo de Shri Manguesh, um dos maiores e mais opulentos de Goa, acolhe peregrinos de todo o Estado que vêm cultuar uma pedra muito antiga. Está ali desde o século XVI, antes mesmo que o actual templo terminasse de ser construído, duzentos anos mais tarde. Veio de Cortalim, povoação na margem sul do Rio Zuari. Salva por um grupo de crentes depois que o templo original foi destruído pela fúria cega dos invasores portugueses. Imagino a epopeia: uma pobre gente em fuga, carregando através da floresta um grande falo de pedra, e atrás desta, num afã de predadores, outra pobre gente, transportando bandeiras e altas cruzes com a imagem de um homem torturado. (AGUALUSA, 2007, p. 149-150)

Além disso, a informação sobre a natureza, a geografia, a paisagem, o clima, o quotidiano, a história, os hábitos e costumes goeses, os conflitos, as peculiaridades - tudo é apresentando através de uma escritura testemunhal pontuada por elementos discursivos de inegável subjectividade. Esses elementos, como sejam excursos reflexivos, fiapos rememorativos de episódios passados, um certo vocabulário mais celebrativo do que descritivo, fazem com que esta narrativa possa ser lida como o registo de aventuras de um sujeito indeciso entre o registo do Oriente e a incontrolável força da imaginação.

As viagens do autor-narrador-personagem visam cartografar, em última instância, as diferentes modalidades de auto-representação goesa, em contexto de subordinação (a uma cultura dominante, a hindu) e de hierarquização cultural, em relação ao modelo colonial português, pois "os mitos imperiais continuam gerando significados, desejos e ações" (PRATT, 1999, p. 15). O "repórter" intenta captar as representações do real: construções imagéticas, (pré)conceitos e estereótipos de que até o narrador não está isento, como quando "ilustra" a vocação 
perdulária dos descendentes com uma anedota sobre estereótipos étnicos na África do Sul (AGUALUSA, 2007, p. 63):

Ao mesmo tempo, intenta-se perscrutar o contexto histórico em que a reinvenção da identidade goesa se processa, rastreando as conexões rizomáticas e as descontinuidades na produção de seus significados culturais. De outra parte, Um estranho em Goa não se limita a escutar e reproduzir dinâmicas de subordinação, nem evidenciar as variáveis da "zona de contacto" (que Mary Louise Pratt diferencia de "fronteira colonial", expressão que legitima a perspectiva expansionista europeia). Antes, pelas conexões entre o "relato de viagem" e as formas de experiência cultural e curiosidade intelectual, procura identificar as descontinuidades e mutações do imaginário colonial e pós-colonial, descobertas nessa demanda do Oriente apresentada de forma dialéctica, inquisitiva e interactiva.

\section{Referências}

AGUALUSA, José Eduardo. Um estranho em Goa. Lisboa: Edições Cotovia, [2000] 2007. AGUALUSA, José Eduardo. “Os bons livros são uma mentira”. Entrevista a Paulo Polzonoff. Rascunho, Rio de Janeiro, ano 5 , n. 53, 2004.

AGUALUSA, José Eduardo. Fronteiras perdidas: contos para viajar. Lisboa: Publicações Dom Quixote, 1999.

BHABHA, Homi K. O local da cultura. Belo Horizonte: Ed. UFMG, 1998.

BARROS, Manoel (de). Livro sobre o nada. Rio de Janeiro: Editora Record, 2004.

BUESCU, Maria Leonor Carvalhão. "O exotismo ou a 'estética do diverso'". In FALCÃO, Ana Margarida; NASCIMENTO, Maria Teresa; LEAL, Maria Luísa (org.). Literatura de viagem; narrativa, história, mito. Lisboa: Edições Cosmos, 1997.

CURVELO, Alexandra. "O poder dos mapas". In CRISTÓVÃO, Fernando (coord.). O olhar do viajante: dos navegadores aos exploradores. Coimbra: Almedina/CLEPUL, 2003.

CHAKRABARTY, Dipesh. "Histórias de minorias, passados subalternos". In SANCHES, Manuela Ribeiro (org.). Deslocalizar a Europa: antropologia, arte, literatura e história na pós-colonialidade. Lisboa: Edições Cotovia, 2005.

CRISTÓVÃO, Fernando (coord.). Condicionantes culturais da literatura de viagens: estudos e bibliografias. Lisboa: Edições Cosmos/CLEPUL, 1999.

DELEUZE, Gilles; GUATTARI, Félix. Mil platôs: capitalismo e esquizofrenia. São Paulo: Ed. 34, 1995.

FREYRE, Gilberto. O mundo que o português criou: aspectos das relações sociais e de cultura do Brasil com Portugal e as colónias portuguesas. Lisboa: Livros do Brasil, 1951. 
GENETTE, Gérard. Palimpsestes: la Littérature au second degré. Paris: Éditions du Seuil, 1982.

KRISTEVA, Julia. Estrangeiros para nós mesmos. Rio de Janeiro: Rocco, [1989] 1994.

KRYSINSKI, W. Carrefour de signes: essais sur le roman moderne. La Haye/Paris/New York: Mouton, 1981.

MEMMI, Albert. Portrait du colonisé, précédé du portrait du colonisateur. Paris : Buchet/ Chastel, 1957.

MORAIS, Carlos Alexandre Morais. A queda da Índia Portuguesa: crónica da invasão e do cativeiro. 2a ed. Lisboa: Editorial Estampa, [1980] 1995.

PRATT, Mary Louise. Os olhos do império: relatos de viagens e transculturação. São Paulo: EDUSC, [1992] 1999.

REIS, Carlos; LOPES, Ana Cristina Lopes. 4a ed. rev. aument. Dicionário de narratologia. Coimbra: Livraria Almedina, 1994.

SAID, Edward. Orientalismo: representações ocidentais do Oriente. Lisboa: Edições Cotovia, [1978] 2004.

SEGALEN, Victor. Essai sur l'exotisme: une Esthétique du divers. Montpellier: Ed. Fata Morgana, 1978.

SHOHAT, Ella \& STAM, Robert. Crítica da imagem eurocêntrica: multiculturalismo e representação. São Paulo: Cosacnaify, 2006.

SMITH, Anthony D. Smith. A identidade nacional. Trad. Cláudia Brito. Lisboa: Gradiva, [1991] 1997.

SOUZA, Teotónio R. de. Some contrasting visions of luso-tropicalism in Índia. In AA.VV., Lusotropicalisme: idéologies coloniales et identités nationales dans les mondes lusophones. Paris: Khartala, 1997.

TODOROV, Tzvetan. A conquista da América: a questão do outro. 3a ed. São Paulo: Martins Fontes, [1982] 2003.

TODOROV, Tzvetan. Nous et les autres: la réflexion française sur la diversité humaine. Paris: Seuil, 1989.

WHITE, Eduardo. Janela para o Oriente. Lisboa: Editorial Caminho, 1999.

WHITE, Hayden. The content of the form: narrative discourse and historical representation. Baltimore/London: The Johns Hopkins University Press, [1987] 1992.

Submetido em 08-07-16

Aprovado para publicação em 17-10-16 